$\begin{array}{lccc}\mathrm{H} 2(90 \mathrm{~min}) & 27(14,59) & 27(11.5,55) & 0.600 \\ \mathrm{CH} 4(0 \mathrm{~min}) & 4(3,5) & 4(3,5.5) & 0.699 \\ \mathrm{CH} 4(30 \mathrm{~min}) & 5(4,6) & 5(3.5,7) & 0.776 \\ \mathrm{CH} 4(60 \mathrm{~min}) & 5(4,5) & 5(3.3,6) & 0.057 \\ \mathrm{CH} 4(90 \mathrm{~min}) & 5(4,5) & 5(4,6.5) & 0.142 \\ \mathrm{H} 2+\mathrm{CH} 4(0 \mathrm{~min}) & 20(12.5,35.5) & 26(9,39) & 0.747 \\ \mathrm{H} 2+\mathrm{CH} 4 & 32(19,50) & 32(12,67) & 0.872 \\ (30 \mathrm{~min}) & & & \\ \mathrm{H} 2+\mathrm{CH} 4 & 31(17,54) & 30(13.5,64.5) & 0.909 \\ (60 \mathrm{~min}) & & & \\ \mathrm{H} 2+\mathrm{CH} 4 & 31(20,63.5) & 31(19,60) & 0.000 \\ & & & \end{array}$

Using Wilcoxon test, $\mathrm{P}<0.05$

Disclosure of Interests: None declared

DOI: 10.1136/annrheumdis-2019-eular.6647

\section{AB0478 PREGNANCY OUTCOME IN WOMEN WITH SYSTEMIC LUPUS ERYTHEMATOSUS TREATED WITH HYDROXYCHLOROQUINE: 10 YEARS EXPERIENCE}

Kyaw Min Tun, Rahana Rahman, Ixora Kamisan @ Atan, Ani Amelia Zainuddin, Ruslinda Mustafar, Mohd Shahrir Mohamed Said. Universiti Kebangsaan Malaysia Kuala Lumpur Campus, Kuala Lumpur, Malaysia

Background: Pregnancy in SLE patients is closely associated with the usage of hydroxychloroquine [1]

Objectives: To determine pregnancy outcomes in women with Systemic Lupus Erythematosus who were treated with hydroxychloroquine in Universiti Kebangsaan Malaysia Medical Centre.

Methods: Pregnant women with Systemic Lupus Erythematosus who had antenatal follow up and delivery in Universiti Kebangsaan Malaysia Medical Centre between $1^{\text {st }}$ January 2007 and $1^{\text {st }}$ January 2017 were retrospectively analyzed. Data collection was done via medical case notes and laboratory investigations. Study population was categorised into two groups based on hydroxychloroquine treatment during pregnancy. Incomplete pregnancy records were excluded.

Results: There were 82 completed pregnancies included with 47 (57.3\%) in $\mathrm{HCQ}$ group and 35 (42.7\%) in non $\mathrm{HCQ}$ group. Amongst $\mathrm{HCQ}$ users, there were significantly more pregnancies with musculoskeletal involvement $(p=0.03)$, heavier mean neonatal birth weight $(p=0.02)$ and prolonged duration of pregnancy $(p=0.001)$. In non-HCQ users, the rate of recurrent miscarriages $(p=0.003)$, incidence of hypertension $(p=0.01)$ and gestational diabetes mellitus $(p=0.01)$ and concurrent medical illness $(p=0.005)$ were significantly more. Hydroxychloroquine use during pregnancy was protective against hypertension $(p=0.001)$ and the gestational age at delivery had significant effect on the neonatal birth weight $(p=0.001)$. However, duration of the disease had significant negative effect on the neonatal birth weight $(p=0.016)$.

Conclusion: $\mathrm{HCQ}$ enhance better neonatal outcomes and reduce adverse pregnancy outcome and antenatal complications such as hypertension and diabetes.

\section{REFERENCES}

[1] M Leroux, C Desveaux, M Parcevaux. Impact of hydroxychloroquine on preterm delivery and intrauterine growth restriction in pregnant women with systemic lupus erythematosus: a descriptive cohort study. Lupus 2015. https://doi.org/10.1177/0961203315591027

Disclosure of Interests: Kyaw Min Tun: None declared, Rahana Rahman: None declared, Ixora Kamisan @ Atan: None declared, Ani Amelia Zainuddin: None declared, Ruslinda Mustafar: None declared, Mohd Shahrir Mohamed Said Paid instructor for: Eli Lilly, Speakers bureau: Eli Lilly DOI: 10.1136/annrheumdis-2019-eular.578

\section{AB0479 RITUXIMAB MAY BE BENEFICIAL IN THE TREATMENT OF SEVERE FORMS OF SYSTEMIC AUTOIMMUNE DISEASES REFRACTORY TO STANDARD IMMUNOSUPPRESSIVE THERAPY. NINE-YEARS EXPERIENCE FROM SINGLE CLINICAL CENTRE}

Marta Olejárova ${ }^{1,2}$, Veronika Balajková ${ }^{1,2}{ }^{1} 1$ st Medical Faculty, Charles University, Clinic of Rheumatology, Prague, Czech Republic; ${ }^{2}$ Institute of Rheumatology, Prague, Czech Republic

Background: Rituximab (RTX) is anti-CD20 monoclonal antibody, registered for the treatment of rheumatoid arthritis (RA). It has been used in clinical practice "of label" in various other conditions including systemic autoimmune diseases - systemic lupus erythematosus (SLE), systemic scleroderma (SScl), Sjögren's syndrome (SjS), polymyositis (PM) and dermatomyositis (DM) and ANCA associated vasculitides, but the results of clinical studies are inconherent. Nevertheless, RTX is frequently used in patients with severe forms of systemic autoimmune diseases with organ involvement after failure of conventional immunosupressive treatment. In Czech Republic, RTX may be used "of label" upon a special request in these special cases.

Objectives: To evaluate indications, clinical characteristics, general efficacy, safety and the impact of RTX therapy in patients with systemic autoimmune diseases treated in the Institute of Rheumatology, Prague since 2009 (a retrospective study).

Methods: The medical reports of all patients treated with RTX for other diagnosis than RA were analyzed and the clinical data (diagnosis, previous treatment with glucocorticosteroids and immunosuppressive drugs, number of RTX infusion, side effects and global evaluation of the efficacy by physician) were collected and analyzed.

Results: In the years 2009 - 2018, 50 patients with various systemic autoimmune diseases were treated with RTX in our clinic (SLE: $n=8$, SjS: $n=2$, SScl: $n=16, P M: n=6$, DM: $n=3$, MCTD: $=1$, ANCA associated vasculitides: $n=11$, overlap syndromes: $n=3$ ). Mean age of the group was $48,12 \pm 12,9$ years at the first RTX treatment and all of the patients experienced previous failure of treatment with 1-6 immunosuppressants. The total number of RTX infusions was 208 with mean 5,32 applications per patient. We have followed the patients for 37,1 months (mean), ranging from 2-114 months. During the follow-up two patients died due to complications of the disease, two patients were lost from the follow-up. The treatment was effective in majority of patients $(n=27)$ and global efficacy was evaluated as "excellent" in 2, "very good" in 10 and "good" in 15 patients. In seven patients the treatment had no effect and in 4 patients the effect could not be evaluated due to short time follow-up. The treatment was well tolerated by patients and we have experienced 39 moderate or severe infections (requiring antibiotics or hospitalization) mostly in patients with ANCA associated vasculitides. In several patients, mild decrease of $\operatorname{lgG}$ levels following the RTX treatment was observed but only in one patient required a subsequent substitution with immunoglobulines. We have not observed any malignancy in the group. The detailed characteristics and results of the patients by diagnosis are provided.

Conclusion: Rixuximab may be beneficial in some patients with severe forms of systemic autoimmune diseases refractory to the standard immunosuppressive therapy. The treatment is generally well tolerated and the infections are the most common side effect.

Acknowledgement: This study was supported by the Research Project No. 0002372801 of the Czech Ministry of Health.

Disclosure of Interests: None declared

DOI: 10.1136/annrheumdis-2019-eular.8276

\section{\begin{tabular}{|l|l}
\hline AB0480 PROLONGED CLINICAL REMISSION AND LOW DISEASE \\
\hline
\end{tabular} ACTIVITY STATUSES ARE ASSOCIATED WITH BETTER QUALITY OF LIFE IN SYSTEMIC LUPUS ERYTHEMATOSUS}

Nareerat Poomsalood, Sumapa Chaiamnuay, Pongthorn Narongroeknawin, Paijit Asavatanabodee, Rattapol Pakchotanon. Phramongkutklao Hospital and College of Medicine, Bangkok, Thailand

\section{Background:}

Treat to target (T2T) strategies in systemic lupus erythematosus (SLE) have been developed in order to control disease activity, improve healthrelated quality of life (HRQoL), reduce organ damage and decrease mortality. Previous studies revealed that both remission and low disease activity (LDA) had comparable damage accrual as well as mortality. However, studies of HRQoL in these two targets are few and there has been no comparative study between them:

Objectives: To determine the association between disease activity status (DAS) and HRQoL in SLE patients.

Methods: SLE patients in out-patient clinic during the previous 12 months were included in the study. Systemic Lupus Erythematosus-specific Quality-of-Life questionnaire (SLEQoL) was measured at the last visit. DAS was determined retrospectively during the previous year. Three categories of DAS were defined: clinical remission (CR): clinical quiescent disease according to Systemic Lupus Erythematosus Disease Activity Index 2000 (SLEDAI-2K), prednisolone < $5 \mathrm{mg} /$ day; low disease activity (LDA): SLEDAI-2K (without serological domain) $\leq 2$, prednisolone $<7.5 \mathrm{mg} / \mathrm{day}$; and non-optimally controlled status: those who were not in CR/LDA. Immuno suppressive drugs (maintenance dose) and antimalarials were allowed. Both CR and LDA have been maintained for at least 1 year. The 